\title{
Psicopatia no ambiente de trabalho
}

\author{
Psychopathy in the workplace \\ La psicopatía en el trabajo
}

Recebido: 04/11/2021 | Revisado: 10/11/2021 | Aceito: 20/11/2021 | Publicado: 22/11/2021

Janine Cristina de Oliveira

ORCID: https://orcid.org/0000-0002-6647-7771 Centro de Ensino Superior de São Gotardo, Brasil E-mail: janinecristina21@gmail.com

Constance Rezende Bovinci

ORCID: https://orcid.org/0000-0002-6952-625X Centro de Ensino Superior de São Gotardo, Brasil E-mail: constancebonvicini@yahoo.com

\begin{abstract}
Resumo
Os psicopatas corporativos refletem de forma negativa as relações socioprofissionais, o que também afeta toda a produtividade de uma organização. O psicopata é um indivíduo sagaz e sem consciência. O seu principal foco é ter status, controle e poder sobre a empresa. Diante do fato, percebe-se a necessidade de se estudar o tema, trazendo de forma mais detalhada e objetiva o perfil do psicopata, o modus operandi, os danos causados a vítima e as implicações jurídicas diante de sua atuação. Para tal foi realizada a abordagem qualitativa, também se utilizou de pesquisas bibliográficas, documental, coletando dados a partir de livros, periódicos, e artigos científicos que condizem com o tema.
\end{abstract}

Palavras-chave: Psicopata; Psicopata corporativo; Organização.

\begin{abstract}
Corporate psychopaths reflect negatively on socioprofessional relationships, which also affects the entire productivity of an organization. The psychopath is a shrewd individual with no conscience. His main focus is to have status, control, and power over the company. In view of this fact, we realize the need to study the subject, bringing in a more detailed and objective way the profile of the psychopath, the modus operandi, the damage caused to the victim, and the legal implications of his actions. To this end, a qualitative approach was used, as well as bibliographic and documental research, collecting data from books, periodicals, and scientific articles that match the theme.
\end{abstract}

Keywords: Psychopath; Corporate psychopath; Organization.

\begin{abstract}
Resumen
Los psicópatas corporativos se reflejan negativamente en las relaciones socioprofesionales, lo que también afecta a toda la productividad de una organización. El psicópata es un individuo astuto y sin conciencia. Su principal objetivo es tener estatus, control y poder sobre la empresa. Ante este hecho, nos damos cuenta de la necesidad de estudiar el tema, aportando de forma más detallada y objetiva el perfil del psicópata, el modus operandi, el daño causado a la víctima y las implicaciones legales de sus acciones. Para ello, se utilizó un enfoque cualitativo, empleando también la investigación bibliográfica, documental, recogiendo datos de libros, publicaciones periódicas y artículos científicos que se ajustan al tema.
\end{abstract}

Palabras clave: Psicópata; Psicópata corporativo; Organización.

\section{Introdução}

Através de notícias, estudos sobre características, perfis, motivações e diferentes tipos de assassinatos em série, com enredos envolvendo desde alienígenas até robôs destituídos de consciência e empatia. A temática desperta tanto interesse que há canais de televisão dedicados quase exclusivamente ao assunto e neles criminólogos de diferentes áreas comentam, sob diversos ângulos, científicos ou não, o modus operandi dos psicopatas, especialmente dentro das organizações. Os psicopatas corporativos são sagazes no ambiente de trabalho e são especialistas em manipulação.

A maneira como os psicopatas agem (modus operadi) no qual baseiam-se em três fases, as quais são: avaliação, manipulação e abandono. Eles buscam se aproximar das pessoas avaliando o valor dos indivíduos e suas fraquezas, lidam com 
futuras presas, manipulando os colegas de trabalho (vitimas) e assim permite que eles se contornem quaisquer ameaças e dificuldades rapidamente perante aos demais funcionários da organização quando são confrontados ou ameaçados.

O assédio moral tem integrado a agenda dos debates corporativos, visando definir os limites de atuação do indivíduo na organização, considerando os princípios garantidores dos direitos humanos. Os primeiros estudos datam da década de 1980, todos realizados em países escandinavos. Estudos quantitativos, o objetivo desses trabalhos consistia em relacionar condutas e consequências relacionadas no ambiente laboral. Essa produção científica inicial ensejou novas pesquisas em todo o mundo sob recortes e delimitações diversas; em geral, com o intuito de compreender o fenômeno e seus mecanismos de incidência. Atualmente, os trabalhos estão mais voltados para a identificação das possíveis origens da conduta e o empreendimento de soluções preventivas

A prática do assédio moral corporativo consolida-se a partir de uma polaridade de influências, onde um polo "comanda" a relação e o outro "aceita" passivamente as coordenadas (temporariamente ou não), incitado por condicionantes diversos. Essa polaridade nem sempre é de natureza funcional, mas, indubitavelmente, cria uma hierarquia invisível, informal e não legitimada de poder. Por esse ângulo, o assédio no âmbito trabalhista também alcança indivíduos pertencentes a um mesmo nível hierárquico.

A metodologia utilizada para a confecção deste trabalho cientifico foi a compilação bibliográfica, em que se baseou na pesquisa de obras de renomados doutrinadores, bem como a análise das normas do ordenamento jurídico brasileiro. Foi feito diversas pesquisas nas bibliografias de doutrinadores, análise de artigos e reportagens com o objetivo de enriquecer este trabalho e levar aos leitores a um conhecimento claro e sucinto do assunto tratado.

A pesquisa possui como objetivo identificar as ações do psicopata no ambiente corporativo, e como isso afeta as relações trabalhistas. Além do mais, colaborando para aspectos das relações interpessoais no ambiente de trabalho, saber como identificar indícios de psicopatia e como agir quando estiver frente a um.

\section{Metodologia}

O método de pesquisa que se utilizou foi a pesquisa qualitativa que segundo (Minayo,2004. p.22) significa "explorar o espectro de opiniões, as diferentes representações sobre o assunto em questão" o que possibilita a grande oportunidade de interação do investigador pesquisador e seu objeto. Baseando-se também de um estudo documental e bibliográfico onde foi feito uma coleta de dados a partir de doutrinadores, livros, sites e artigos científicos que condizem com o tema.

\section{Psicopata Corporativo}

A literatura relacionada a psicologia forense fornece inúmeros exemplos de personalidades psicopáticas que assombraram e assombram o universo, históricos assassinos em série (serial killers); assassinos calculistas; filhos que assassinam pais, irmãos; pais, mães, padrastos e madrastas que assassinam filhos, entre tantos outros crimes hediondos que foram motivados por personalidades psicopáticas. Segundo (Horta,2001) pesquisas realizadas em empresas americanas apontam que até 3,9\% dos executivos de empresas podem ser psicopatas, depois dos presídios o ambiente onde mais se concentram personalidades psicopáticas é no mercado de trabalho.

\subsection{O Perfil do Psicopata Corporativo}

São inúmeros os conceitos, definições e linhas de estudo que buscam definir a personalidade psicopática. A expressão psicopata vem do grego: psyche, mente; pathos: doença, o que leva a uma falsa interpretação de que os psicopatas são doentes mentais. Segundo (Silva,2008) “os psicopatas não podem ser encaixados nas definições de doentes mentais tradicionais.” 
Os psicopatas consistem num conjunto de traços de personalidade específicos. Podem causar boa impressão, logo de primeira vista, e são tidos como "normais" pelos que conhecem superficialmente. A verdade é que não existem nenhum problema mental, muito pelo contrário, tem discernimento no que fazem, são muito inteligentes, mas não possuem sentimentos, podem até demonstrar, devido ao convívio com as pessoas que estão a sua volta, mas sem realmente sentir.

O psicopata é incapaz de entender fatos e valores pessoais, ele não tem empatia, e sensações humanas não tem significado para ele; tudo isso não pode ser explicado pelo psicopata, pois ele não consegue compreender. (Cleckey,1941. p.29) O psicopata pode até repetir as palavras e dizer que compreende, mas nem ele consegue perceber que não entende verdadeiramente. São manipuladores, e conseguem facilmente ganhar a confiança das pessoas.

Para conseguir uma vaga em uma empresa, antes mesmo de entrar, ele estuda todo o histórico da organização, de forma que no dia da entrevista, ele apresente um currículo impecável e sabendo até mais que o próprio entrevistador, assim, consegue convencê-lo com um ótimo argumento, respondendo a tudo que o entrevistador quer ouvir, e percebendo que ele é o funcionário que a empresa precisa no momento o contrata. Nessa fase no momento da entrevista ter profissionais qualificados para identificálos seria uma forma de conter esses indivíduos dentro do ambiente laboral. Ao passar dessa etapa o psicopata já começa a sua caça no ambiente de trabalho, estudando e observando as pessoas a sua volta, busca conhecer principalmente quem são os mais próximos dos chefes, pois o primeiro passo para identificar esse perfil é que são egocêntricos, se consideram melhores que os outros e fazem de tudo para destruir quem estiver em seu caminho, tudo isso para ter poder e estar no controle.

Analisando, e buscando informações sobre o ambiente, ele cria o seu espaço dentro da empresa, sempre muito simpático, sendo um bom amigo, pronto para ouvir tudo que o seu colega de trabalho tem a dizer, ele é exatamente aquele tipo de perfil que se transforma no que a pessoa precisa naquele momento, mas antes disso ele precisa conhece-la bem, com isso ele cria laços, as pessoas começam a confiar, porque ele é um bom ouvinte e um ótimo articulador, o psicopata consegue com seu charme e inteligência seduzir as pessoas de uma forma que elas começam a contar sobre suas vidas pessoais , e é onde mora o perigo, pois ele se utiliza dessas informações para usar contra a vítima mais tarde.

A grande maioria dos psicopatas realizam suas atividades profissionais para conquistar poder e controle sobre as pessoas. Nesse contexto e segundo a autora (Silva,2014), podemos encontrar policiais que dirigem redes de prostituição, juízes que cometem os mesmos delitos que os réus, mas no julgamento os condenam com argumentações jurídicas impecáveis.

Também é importante destacar, a presença dos psicopatas em casos de pedofilia, para realizarem tal perversidade, os psicopatas se camuflam em profissões para se aproximarem de crianças. São professores, treinadores, esportivos, pediatras, entre dezenas de profissões que exigem contato com as crianças. O impacto dano que as condutas dos psicopatas corporativos possuem sobre as relações socioprofissionais e, por conseguinte, na produtividade da companhia, torna-se extremamente necessário estudar sobre esse tema.

\subsection{O Modus Operandi do psicopata corporativo}

O psicopata corporativo, segundo (Babiak\&Hare,2006) são indivíduos sagazes no ambiente laboral e são especialistas em manipulação.

Segundo os pesquisadores existem três fases que o psicopata se utiliza para as suas táticas e estratégias que fazem parte do seu modus operandi dentro de uma organização. A primeira fase é a avaliação, o psicopata avalia o ambiente, identifica as pessoas, principalmente aqueles que são influentes na organização como os cargos de liderança e poder. A intenção de início do psicopata é criar uma falsa amizade com as vítimas, identificando suas fraquezas, pois, em algum momento podem ser úteis para eles. 
O psicopata observa as pessoas que podem ser úteis para eles no ambiente de trabalho, após se aproximarem dessas pessoas, criam um certo charme, mentiras e enganos, e já ocorre a segunda fase do modus operandi, a manipulação; jogar uns contra os outros, humilhar, e tornar a convivência dos indivíduos da empresa ainda mais difíceis.

Segundo (Silva,2014) os psicopatas não vão ao trabalho, vão a caça. Ele pode criar um caráter fictício para manipular as pessoas ao seu redor, fazendo falsos elogios e tecendo comentários que não são verdadeiros.

Ao passar pelas etapas de avaliação e manipulação, vem a terceira etapa que é o abandono, o psicopata consegue deixar a sua vítima esgotada e desorientada, e são abandonadas no momento em que não são mais úteis e procura outras pessoas para explorar e drenar suas energias. O afastamento é frequentemente inesperado, ou seja, o psicopata simplesmente desaparece e pode acontecer que a vítima não perceba a troca por outro alvo. Esses indivíduos com esse tipo de transtorno enxergam os colegas de trabalho como peões para serem usados, manipulados de acordo com as regras do psicopata.

A pesquisadora (Silva,2014), relata que colocando os colaboradores uns contra os outros em especial os gestores, o psicopata assumem o lugar do seu superior de forma imediata, isso ocorre quando os mesmos são desligados das empresas ou rebaixados de cargo e função. A forma de agir, ausência de medo, empatia e de consciência tornam esse indivíduo potencialmente maquiavélicos e perigosos, o que facilita o seu desempenho na empresa.

A forma como as corporações são estruturadas, pode colaborar para que os indivíduos com comportamentos egocêntricos e desonestos alcancem cargos de liderança e poder. No mundo corporativo, segundo Silva a competividade entre as empresas pode obter proporções, provocando crises em muitos setores empresariais, com isso a troca de colaboradores é significante, $\mathrm{o}$ ambiente empresarial extremamente competitivo fazem com que algumas corporações busquem por esse perfil de profissional ,que o psicopata sabe desenvolver como ninguém.

Os pesquisadores (Babiak\&Hare,2006) afirmam que: o clima empresarial de hoje, acelerado, competitivo e muitas vezes caótico, promove o estimulo que os psicopatas buscam e dá cobertura suficiente para o seu comportamento manipulativo e abusivo.

Como exposto acima, as instituições com frágil estruturação administrativa, se voltam, em circunstâncias emergenciais em profissionais que interpretam o papel de salvador da pátria. Nessa organização o colaborador que demonstra força, capacidade de convencimento e controle das emoções rapidamente se destacará, pois são essas características de destaca no mundo dos negócios.

Na opinião da autora (Silva,2014), um psicopata de forma encantadora e manipuladora pode simular tais atributos, de forma deficiente no enfoque material, ideológico ou ético dentro da empresa, podendo assim construir uma carreira longa e de êxito dentro da corporação. A autora relata que a presença de psicólogos na corporação seria um diferencial para identificar de modo analítico e cético os currículos impecáveis que são apresentados no momento da entrevista. Nem sempre o entrevistador é devidamente qualificado e instruído para analisar os talentos de persuasão e manipulação do psicopata.

\section{Os Danos Causados as Vítimas pela Atuação do Psicopata Corporativo}

\subsection{Psicopatas corporativos e o assédio moral no trabalho}

$\mathrm{O}$ assédio moral, traz como definição qualquer conduta abusiva, gesto, palavra ,comportamento ,atitude, que segundo (Herigoyen,2001) atende contra a dignidade ou integridade psíquica ou física de uma pessoa ,ameaçando seu emprego ou degradando o clima de trabalho.

Em se tratando de abuso de poder, o assédio moral é um mecanismo utilizado por indivíduos perversos, (Freitas,2001). A atuação do psicopata corporativo em alguns contextos organizacionais se dá pela flexibilidade do local, ou seja, alguns locais são mais propícios, algumas características como o estresse, a má comunicação, a falta de reconhecimento, á fuga a responsabilidade e a competição extrema, acabam por tornar o ambiente mais suscetível ao psicopata corporativo para atuar. 
Divergências entre funcionários dentro de um ambiente de trabalho saudável, são comuns e fazem parte do dia-a-dia, porém quando as desavenças passam a violência, desrespeito e perseguição, podem configurar assédio moral.

O assédio moral no trabalho é uma situação que acontece a muito tempo. Ele se caracteriza por condutas antiéticas que colocam o funcionário em algumas situações constrangedoras e humilhantes, de maneira intencional. (Marazzo,2017)

Todos os atos e comportamentos provindos do patrão, gerente, superior hierárquico ou dos colegas, que representem uma atitude de continua e ostensiva perseguição que possam causar danos importantes as condições físicas, psíquicas e morais da vítima podem se enquadrar nessa categoria. (Guedes,2003)

Segundo Medeiros, Valadão e Possas (2014) há uma intensa padronização imposta aos funcionários admitidos em empresas, seguido de pressões para incorporação das regras organizacionais na tentativa de transformar sua forma de vestir, de agir e de pensar, o que pode acarretar em um afastamento das pessoas que não se submetem a esses padrões, tornando-as possíveis focos de assediadores.

A violência gerada contra o empregado, portanto, tem inúmeras consequências, trazendo prejuízos na produtividade do empregador. As consequências não se limitam apenas ao subordinado, mas também, a pessoa por trás das agressões em decorrência de seus atos. O fruto de suas atitudes pode não lhe afetar psicológica ou moralmente, mas economicamente, como indenização, suspensão de privilégios no ambiente de trabalho ou até mesmo a perca do emprego. É importante que os funcionários saibam identificar e se defender de situações de assédio, e se necessário pedir ajuda a colegas, assim, impedindo que essas circunstâncias aconteçam novamente ou se agravem.

\subsection{Como identificar e lidar com os psicopatas corporativos}

Fiorelli e Mangini (2018) ao analisarem as peculiaridades referentes a psicopatia, elucidaram uma característica de suma importância. Está sendo a concepção desse transtorno, que se tem o início na infância ou mesmo na fase da adolescência e na fase adulta acaba por permanecer.

Trindade (2004) em sua obra, assevera que os indivíduos diagnosticados com o transtorno de personalidade insociável possuem a tendência a ser mais “destruidores e prejudiciais emocionalmente", e ainda a desordenar o ambiente e ao meio social em que vivem. Os psicopatas não possuem, valores ou comportamentos de acordo com o que denominamos de correto, possuem a necessidade de lesar, embaraçar o próximo, e quando conseguem atingir o alvo, os mesmos não se sentem culpados, ansiosos e nem sentem a necessidade de corrigir seu erro.

Inúmeras são as particularidades direcionadas para se identificar um psicopata, e é de suma importância ressaltar que os mesmos podem sofrer alterações com o passar do tempo, devido a cultura, adicionando outras características ou retirando algumas delas.

Um psiquiatra americano (Cleckley,1941/1976), também apontou algumas das principais características observadas em um portador de psicopatia, enumerando elas:

(1) charme superficial e boa inteligência, (2) ausência de delírios e outros sinais de pensamento irracional, (3) ausência de nervosismo, (4) não confiável, (5) falsidade e falta de sinceridade, (6) ausência de remorso ou vergonha, (7) comportamento antissocial inadequadamente, (8) julgamento deficitário e falha em aprender com a experiência, (9) egocentrismo patológico e incapacidade de amar, (10) deficiência geral nas reações afetivas principais, (11) perda específica de insight, (12) falta de resposta nas relações interpessoais gerais, (13) comportamento fantástico e desagradável com bebida e às vezes, sem, (14) suicídio raramente concretizado, (15) vida sexual e interpessoal trivial e deficitariamente integrada e (16) fracasso em seguir um plano de vida. 
Ressaltando que Psicopata não é somente aquele que pratica crimes, mas todo aquele que possui as características supracitadas. (Daynes,2012. p.34), ao escrever em seu livro "Como identificar um psicopata", informou que "os cientistas calculam que entre $1 \%$ e 3\% da população em geral seja psicopata. Portanto, se você tem cem amigos no Facebook, pelo menos um deles pode ser um psicopata".

Há uma subdivisão (classificação) da psicopatia, sendo ela primária e secundária. O que vai determinar a caracterização da verdadeira psicopatia é a presença de ansiedade. Será primária, aquela caracterizada como prototípica, quando o indivíduo cometer "[...] atos antissociais, é irresponsável, não tem empatia e é superficialmente charmoso". E será secundária, aquele psicopata que age de forma impulsiva em decorrência da ansiedade, e pratica violência. (Huss,2011.)

Até a década de 1980, era difícil identificar o psicopata, haja vista que não possuía um método padrão para fazer tal análise. Devido a essa dificuldade de diagnóstico, Robert Hare, criou o Psychopathy checklist (PCL), em 1980 e o Psychopathy checklist-Revised (PCL-R), em 1991, a fim de avaliar a psicopatia. Sendo o último, o mais adequado para identificar os fatores de risco de violência (Trindade, 2004).

O PCL-R, é uma lista de 20 sintomas, que será analisado rigorosamente, por um profissional competente a fim de pontuar cada um dos itens para se chegar a 19 um diagnóstico. (Huss,2011.p.95) explicou como é feita essa pontuação.

Cada termo é avaliado em uma escala de 3 pontos variando de 0 a 2 . Um escore de 0 indica a ausência de um sintoma, 1 indica a possível presença de um item e 2 é pontuado se o sintoma for definitivamente exibido pelo examinando. [...] Como o PCL-R é pontuado de 0 a 2 nos 20 itens, os escores variam de 0 a 40 na medida. Um escore acima de 30 é considerado um ponto de corte conservador para psicopatia.

Trindade (2004) constatou ainda sobre o diagnóstico que quando há um crime e o infrator, maior de 18 anos, apresenta características de que possui alguma doença mental ou se preenche os critérios usados para diagnosticar o TPAS, é chamado os psicólogos para fazerem uma análise e diagnosticarem-no, a fim de verificar se enquadrará nos casos de inimputabilidade. Já para as crianças e adolescentes, não há o que se falar em diagnóstico tendo em vista que sua personalidade ainda está em desenvolvimento.

\section{Responsabilidade Criminal do Psicopata Corporativo}

O Direito Penal Brasileiro possui finalidade de manter a paz social, utilizando-se de normas mandamentais e proibitivas. Ao se deparar com a ocorrência de um determinado delito é verificado se preenche os elementos e sub- elementos para a definição de crime, sendo eles, adotados pelo sistema analítico e teoria tripartida: Fato típico; ilícito e culpável. (Masson,2017)

A proteção jurídica para manter a paz social que o Direito Penal propõe, visa resguardar a sociedade dos atos praticados por indivíduos, sendo eles doentes mentais ou não. Devido a isso há uma necessidade de compreender a imputabilidade daquele que praticou o delito a fim de buscar compatibilidade de punição para determinada conduta. (Trindade,2004)

Ao desmembrar a culpabilidade, depara-se com um dos elementos principais, a imputabilidade do agente. Sendo esta, de acordo com a teoria adotada pelo Código Penal brasileiro e (Capez,2012), a capacidade de entender o caráter ilícito de determinada conduta, podendo ser omissa ou comissiva, e mesmo após a percepção da contrariedade da lei, possuir a vontade de praticar o delito.

\subsection{Posição doutrinária}

Assim, os imputáveis são aqueles que entendem o caráter ilícito, mas mesmo assim praticam a conduta delitiva. O que se indaga, é o que acontece com os psicopatas que cometem o ato ilícito; são ou não considerados inimputáveis? Para (Huss, 
2011), nem todo psicopata comete crime; portanto serão analisadas as consequências dos atos de um indivíduo que possui esse transtorno e pratica uma conduta delituosa.

A regra é que todos são imputáveis, porém, admitindo a existência de exceções, o Código Penal brasileiro prevê circunstancias a fim de afastar as imputabilidades, sendo os casos de: menoridade, doença mental, desenvolvimento mental incompleto, embriaguez completa oriundas de força maior ou por caso fortuito. (Masson,2017)

O direito penal busca punir o cometimento de um fato típico, ilícito e culpável de um agente, e essa punição denominase de sanção penal. (Masson,2017. p.611) conceituou-a como sendo a "[..] resposta estatal, no exercício do ius puniendi e após o devido processo legal, ao responsável pela prática de um crime ou de uma contravenção penal.” Observou ainda que há duas espécies das sanções punitivas: Penas e Medidas de segurança.

As penas, para (Capez,2015), possuem finalidades específicas que se justificam por meio das seguintes teorias: Absoluta ou retribuição; relativa, finalista, utilitária ou da prevenção; e mista, eclética, intermediária ou conciliatória.

O pesquisador (Greco,2011) observou que o Código Penal Brasileiro unificou as teorias: Absolutas (aquelas em que o Direito Penal possui caráter de reprovação) e relativas (que resguarda somente a prevenção), chegando a origem da Teoria Mista, em que as penas possuem caráter finalístico de reprovação do cometimento de condutas ilícitas e prevenção de futuras práticas do crime.

O Código Penal Brasileiro, antes da reforma de 1984, era adepto ao sistema duplo binário, que significava que o indivíduo inimputável ou semi-imputável ao praticar o delito, cumpria primeiramente a pena privativa de liberdade e posteriormente era aplicada a medida de segurança. Adotou o sistema vicariante, que é a adoção da sanção penal cumulativa em pena (privativa de liberdade, restritiva de direito, multa), aplicável aos imputáveis e a medida de segurança para os inimputáveis e semi-imputáveis (CAPEZ, 2011).

As penas possuem uma subdivisão dependendo do crime cometido pelo agente, sendo elas descritas no tipo legal: pena privativa de liberdade; restritiva de direito e multa. A pena privativa de liberdade, possui como espécie a reclusão, detenção e prisão simples nos casos de contravenções penais, podendo ser cumprida em regimes fechados, semiaberto e aberto dependendo da quantidade de anos da penalidade prevista no preceito secundário. Para (Masson, 2017), a pena privativa é aquela que:

Retira do condenado o seu direito de locomoção, em razão da prisão por tempo determinado. Não se admite a privação perpétua da liberdade (CF, art. 5, XLVII, “b”), mas somente a de natureza temporária, pelo período máximo de 30 (trinta) anos para crimes (CP, art. 75) ou de 5 (cinco) anos para contravenções penais (LCP, art. 10) (2017, p. 623)

O ministro Sebastião Reis Júnior, relator dos autos do Habeas Corpus na 462.893- Ms(2018/0197852-1) observa que o psicopata possui a capacidade de compreender a ilicitude do ato por ele praticado, visto a falta de freios sociais, falta de empatia ou remorso na prática de seus atos, afirma que:

[...] apesar da psicopatia não ser considerada uma moléstia mental, ela pode ser vislumbrada como uma ponte de transição entre o psiquismo normal e as psicoses funcionais, sendo assim, os agentes psicopatas devem ser tidos como semi-imputávies. (Brasil,2019,s.p)

Em outro entendimento, o desembarcador Odone Sanguine nos autos da apelação criminal n ${ }^{\circ}$ 9089/TJ-RS observa que o transtorno antissocial não influencia na capacidade de entendimento da ilicitude do ato, dessa forma, é necessário o reconhecimento da imputabilidade do psicopata (Rio Grande do Sul) 
As penas restritivas de direito é uma aplicação substitutiva das penas privativas de liberdade, em que são impostas medidas diversas das que são aplicadas referentes à restrição do direito de locomoção do indivíduo. (Capez,2015) disse que "Não se trata de penas, mas de institutos que impedem ou paralisam a persecução penal, não se confundindo, portanto, com as penas alternativas"

A duração das penas restritivas de direito tem previsão legal no artigo 55 do Código Penal, será igualitária as penas privativas de liberdade que foram substituídas. Ainda acerca das penas restritivas de direito, o Supremo Tribunal Federal redigiu um HC sobre a necessidade de aplicá-las, sendo:

As penas restritivas de direitos são, em essência, uma alternativa aos efeitos certamente traumáticos, estigmatizantes e onerosos do cárcere. Não é a toa que todas elas são comumente chamadas de penas alternativas, pois essa é mesmo a sua natureza: constituir-se num substitutivo ao encarceramento e suas sequelas. E o fato é que a pena privativa de liberdade corporal não é a única a cumprir a função retributivo-ressocializadora ou restritivo-preventiva da sanção penal [...] (Masson,2017)

O rol para aplicação é taxativo, conforme o artigo 43 do Código Penal prevê, sendo elas "prestação pecuniária; perda de vens e valores; prestação de serviços à comunidade ou a entidades públicas; interdição temporária de direitos; limitação de fim de semana", possuindo as seguintes características: substitutividade em relação à aplicação das penas privativas de liberdade, e autonomia sendo que uma vez aplicadas não cabe cumulação com outra espécie de pena. (CAPEZ,2015)

Para a aplicação dessa medida substitutiva, é necessário que preencha alguns dos requisitos elencados no artigo 44 do Código Penal, sendo eles: a pena aplicada deve não superior a 4 anos e o crime cometido não poderá ser mediante violência ou grave ameaça; não pode haver reincidência de crime doloso; e um critério subjetivo sendo que deverá ser observado a culpabilidade, antecedentes criminas, conduta social, personalidade do condenado, motivos e circunstancias a fim de que essa substituição seja suficiente para sua aplicação. (Greco,2011)

A outra forma de sanção é a medida de segurança, aplicada àqueles indivíduos que praticarem crimes e forem considerados imputáveis ou semiimputáveis com índices de periculosidade, de caráter preventivo a fim de não praticarem novas infrações penais; e terapêuticas, com escopo de evitar a ocorrência de outras condutas criminosas.

O (Masson,2017. p.957) estabeleceu requisitos para a aplicação da medida de segurança, sendo eles: "(1) prática de um fato típico e ilícito; (2) periculosidade do agente; (3) não tenha ocorrido a extinção da punibilidade". Sendo de suma importância que haja a prática do crime, autoria e materialidade, a verificação de grande índice para a prática de novas condutas delitivas, e que não se enquadre nos casos de extinção da punibilidade.

$($ Capez,2015) ao tratar sobre os pressupostos da concessão da medida de segurança informou que nos casos em que haja periculosidade recebe tratamentos distintos a inimputabilidade da semi-imputabilidade. Haja vista que para ser declarada a inimputabilidade basta que se tenha um laudo diagnosticando tal doença, conhecida como periculosidade presumida, já nos casos de semiimputabilidade, é necessária que haja constatação do juiz, mesmo se já houver sido feito laudos especificando a doença, conhecida como periculosidade real.

A aplicação da medida de segurança se dá com a expedição de guia de internação para a execução, haja vista que só é possível a internação em Hospital de Custódia e Tratamento Psiquiátrico com essa guia, remetida à autoridade administrativa responsável pela execução, conforme dispõe a os artigos 171 e 173 da Lei de Execução Penal.

O (Bitencourt,2012) dissertou sobre os tipos de estabelecimento em que será cumprida a medida de segurança, sendo eles: hospital de custódia e tratamento psiquiátrico, conhecido como o "velho e deficiente manicômio judiciário"; estabelecimento adequado, por ter características hospitalares também se considera os manicômios; e por fim, o local com dependência médica adequada. 
De acordo com $($ Greco,2011) não há prazo determinado para o cumprimento dessa medida, pois persistirá enquanto durar o tratamento e o indivíduo estiver recuperado e pronto para viver em sociedade, por meio de diagnóstico de perícia médica, conhecida como Cessação da periculosidade.

Alguns doutrinadores discordam acerca desse prazo indeterminado, pois acreditam que ofende o princípio constitucional da vedação da prisão perpétua, devido a isso sugerem que esse tratamento deve observar os limites máximos previstos no preceito secundário do tipo legal. Com esse pensamento, (Bitencourt,2012. p.643) se posicionou:

Começa-se a sustentar, atualmente, que medida de segurança não pode ultrapassar o limite máximo da pena abstratamente cominada ao delito, pois esse seria 'o limite da intervenção estatal, seja a título de penal, seja a título de medida', na liberdade do indivíduo, embora não prevista expressamente no Código Penal, adequando-se à proibição constitucional do uso da prisão perpétua.

O pesquisador (Bitencourt,2012) estabeleceu algumas diferenças entre pena e medida de segurança. Para ele as penas possuem caráter retributivo preventivo, o prazo para duração é determinado, são aplicadas aos imputáveis e em alguns casos aos semi-imputáveis e o seu fundamento é a culpabilidade. Já para a medida de segurança, tem natureza preventiva, seu prazo é indeterminado, findando quando o tratamento devido se concluir, são aplicadas aos imputáveis e também em alguns casos aos semi-imputáveis, possuindo fundamento na periculosidade.

As espécies de medida de segurança estão previstas no artigo 96 do Código Penal, (Masson,2017) defende que em seus inícios demonstram que as espécies possuem caráter detentivo, em que ocorrerá quando o indivíduo for internado em hospital de custódia e tratamento psiquiátrico ou em outro estabelecimento, e restritivo, o caso do inciso II, ao sujeitar o indivíduo a um tratamento ambulatorial. Ainda no artigo 97 do código penal, dá a faculdade ao julgador de escolher o melhor tratamento para aquele que praticou a conduta delituosa e se enquadre nos requisitos de imputabilidade.

\subsection{Posição Jurisprudencial}

A avaliação dos casos reclama prudência e análise circunstanciada do fenômeno por parte do magistrado, igualmente dos demais operadores do direito e atores envolvidos. Uma descrição desatada do contexto pode induzir qualquer intérprete à configuração do assédio moral e, na verdade, ser tão somente uma ficção da suposta vítima, que apenas visualiza o fato de uma perspectiva contaminada por sua auto visão. Significa afirmar que o indivíduo pode imprimir sentido a um fato (série de atos) a partir da imagem que tem sobre si mesmo, igualmente, de seus sentimentos e carências. Um dos óbices à identificação do assédio moral é que as abordagens do assediador em relação ao assediado são interpretadas como brincadeiras inocentes, mascarando seu real propósito. A análise dos casos revela o grau de dificuldade para compor a prova. Por essa razão, a jurisprudência nacional é rica em posicionamentos contrários àquele pretendido pelo assediado, negando a indenização pretendida.

Assédio Moral no Trabalho. Dever de Reparar. Assédio moral, "bullying" ou terror psicológico, no âmbito do contrato de emprego consiste na conduta abusiva do empregador ao exercer o seu poder diretivo ou disciplinar, atentando contra a dignidade ou integridade física ou psíquica de um empregado, ameaçando o seu emprego ou degradando o ambiente de trabalho, expondo o trabalhador a situações humilhantes e constrangedoras. Assim, estará configurado pela repetição de condutas tendentes a expor a vítima a situações incômodas ou humilhantes, com a finalidade específica de ocasionar um dano psíquico e social à vitima, marginalizando-a em seu ambiente de trabalho. Todavia, para se imputar ao empregador o dever de reparar o dano sofrido pelo empregado (que se caracteriza pelo próprio evento), a conduta culposa ou dolosa deve ser comprovada, de forma insofismável, pelo empregado (art. 186 do Código Civil). (TRT-3 - 
RO: 00181201405103004 0000181-48.2014.5.03.0051, Relator: Emerson Jose Alves Lage, Primeira Turma, Data de Publicação: 18/07/2014 17/07/2014. DEJT/TRT3/Cad. Jud. Página 36. Boletim: Não.)

O psicopata pode cometer assédio moral, sendo enquadrado no crime de calúnia, é quando o assediador acusar o assediado pela prática de um crime não cometido, conforme artigo 138 do Código Penal: Caluniar alguém, imputando-lhe falsamente fato definido como crime. Pena -detenção, de seis meses a dois anos, e multa. Sua Pena é detenção de seis meses. Assim como ofender a honra da vítima, poderá ser caracterizado crime de difamação, nos termos do artigo 139 do Código Penal: Difamar alguém, imputando-lhe fato ofensivo à sua reputação, punível com detenção de três meses a uma ano mais multa."

Como repercussão de vários casos de assédio moral, em 2019 com a aprovação do Projeto de lei 4742/01, a Câmara dos deputados tipificou no Código Penal, o crime de assédio moral no ambiente de trabalho. A proposta está em debate no Senado.

O crime será caracterizado quando alguém ofender reiteradamente a dignidade de outro, causando-lhe dano ou sofrimento físico ou mental no exercício de emprego, cargo ou função.

O exame das argumentações denuncia que os tribunais compartilham o entendimento de que o genuíno poder disciplinar não exorbita os limites impostos pelas normas organizacionais lícitas (explícitas ou não), muito menos, implica sujeição da pessoa àquela do empregador por meio de privação das liberdades. No plano do "ser" (existencial), aquele substantivo, o reconhecimento valorativo da dignidade humana é a amálgama que equilibra e harmoniza as dualidades das relações sociais.

De fato, o fenômeno jurídico objeto desse estudo evidencia a impossibilidade de analisá-lo e compreende-lo sem lançar um olhar para os pressupostos que alicerçam a concepção da dignidade humana: liberdade, coexistência social e solidariedade. "A dignidade da pessoa humana é o epicentro das normas constitucionais, o sustentáculo dos direitos fundamentais e a base dos direitos de personalidade".

\section{Conclusão}

A revisão sobre o objeto de pesquisa especificado na elaboração do artigo cientifico visou o alcance dos objetivos específicos para atingir o objetivo geral e respondendo a pergunta -chave do artigo em questão.

A definição e a caracterização, no que diz respeito ao psicopata corporativo foram apresentados vários pensamentos de pesquisadores brasileiros e estrangeiros sobre o tema. A principal característica do psicopata é ausência de consciência. Ele tem ciência de seus atos praticados e das respectivas consequências para as vítimas. O perfil do psicopata foi detalhado e explicado.

O modus operandi do psicopata corporativo foi perscrutado por autores da temática. As estratégias de manipulação foram evidenciadas, pois o psicopata da deseja poder e controle na organização, manipular os colaboradores para obter vantagem em cima de suas ideias.

Os danos causados as vítimas pela atuação do psicopata corporativo, o prejuízo causado a vítima e a possibilidade de desenvolver depressão. A insegurança e a perda de confiança nas próprias capacidades e nos demais membros da corporação.

O estudo do caso apresentado alcançou os objetivos específicos já citados definidos anteriormente e, por conseguinte estabeleceram o objetivo geral estabelecido. A pesquisa desenvolvida ajudou a explicar as definições, o perfil, o modus operandi e os efeitos causados nas vítimas pela atuação do psicopata corporativo dentro do ambiente laboral.

Por fim, foi apresentado a responsabilidade criminal do psicopata, o posicionamento do ordenamento jurídico brasileiro, afim de estabelecer critérios específicos e adequados para tratar do psicopata corporativo em seus diversos graus de perversidade dentro de uma organização. 
Research, Society and Development, v. 10, n. 15, e383101522788, 2021

(CC BY 4.0) | ISSN 2525-3409 | DOI: http://dx.doi.org/10.33448/rsd-v10i15.22788

\section{Referências}

Babiak, P., \& Hare, R. (2006). Snakes in suits: When psychopaths go to work,

Brasil. Superior Tribunal de Justiça. (2019). Habeas Corpus nº 462.893 -MS (2018/0197852-1). Relatora: Sebastião Reis Júnior.

Capez, F. (2012). Curso de direito penal: parte geral. editora Saraiva.

Capez, F.(2015). Curso de direito penal: parte geral. editora Saraiva.

Clecklely, H. (1941) The Mask of Sanity (A Máscara da Sanidade)

Daynes, K. \& Fellowes J. (2012) Como identificar um psicopata: cuidado! Ele pode estar mais perto do que você imagina. São Paulo: Cultrix, 34.

Fiorelli, J. \& Ragazzoni.R.(2018) Psicologia Jurídica. Atlas.

Freitas, M.(2001) Assédio sexual: faces do poder perverso nas organizações. RAE - Revista de Administração de Empresas, $41(2)$, 8- 19.

Greco, R.(2011) Curso de direito penal. Impetus.

Guedes, M. (2003). Terror psicológico no trabalho.

Hirigoyen, M.(2001) Assédio moral - A Violência Perversa no Cotidiano - Tradução de Maria Helena Kühner. (5a ed.), Bertrand do Brasil, p. 65.

Horta, M. Psicopatas no Trabalho. Revista Super Interessante. (291a ed.), http://super.abril.com.br/comportamento/psicopatas-sa .

Huss, M. T. (2017) Psicologia Forense. Artmed Editora S.A, 2011.Marazzo, Lucy Moraes de; Meiriño, Marcelo Jasmin; Méxas, \& Mirian Picinini;2017

Masson, C. (2017) Direito penal esquematizado: parte geral-vol. 1. (11a ed.), MÉTODO, 2017

Medeiros, C. R. O.; Júnior, V. M. V., \& Possas, M. C. (2014) Quem mais veste Prada?” Psicopatas Corporativos e Assédio Moral no Trabalho. XVII SEMEAD Seminários em Administração. http://sistema.semead.com.br/17semead/resultado/trabalhosPDF/489.pdf.

Minayo, M. C. S. (2004) O Desafio do Conhecimento. Hucitec.

Rio grande do Sul. Tribunal de Justiça. (2011). Ap. crim. 70037449089, rel. Des. Odone Sanguine.

Silva, A. (2008). Mentes Perigosas - O Psicopata Mora Ao Lado.

Silva. A. (2014) Mentes Perigosas - O Psicopata Mora ao Lado.

Trindade, J.(2004) Manual de Psicologia Jurídica para operadores do direito. Porto Alegre: Livraria do Advogado Editora. 